\title{
MOMENTINHO CULTURAL MOTIVANDO A INTERAÇÃO NAS AULAS DE ESTATÍSTICA
}

\author{
Filipe J Zabala e Thaísa J Müller \\ Pontifícia Universidade Católica do Rio Grande do Sul, Brasil \\ filipe.zabala@pucrs.br
}

\begin{abstract}
A proposta apresentada neste artigo tem por objetivo promover a interação e motivação dos estudantes, que por vezes percebem algumas disciplinas como dificeis ou entediantes. $O$ denominado "Momentinho Cultural" faz parte desse processo, uma vez que representa um intervalo oficializado nas aulas para que sejam tratados assuntos de interesse comum. Por meio de atividades que sejam atrativas aos alunos é possivel aumentar sua atenção e motivação nos conteúdos específicos desenvolvidos nas disciplinas. Além disso, o Momentinho Cultural tem também a característica de promover uma maior aproximação da turma com temas ligados à arte e variedades, promovendo a formação integral do ser humano, algo que muitas vezes tem sido deixado de lado nos dias atuais.
\end{abstract}

\section{INTRODUÇÃO E HISTÓRICO}

A ARTE precede a Ciência. Em 1634 foi publicado Somnium (O Sonho), escrito em 1608 pelo matemático e astrônomo Johannes Kepler (Kepler and Rosen (1967)), considerado por Carl Sagan e Isaac Asimov o precursor da ficção científica. Kepler descreve como um observador enxerga a Terra vista da Lua, conquistada pelo ser humano somente em 1969. O intervalo de 1969 $-1608=361$ anos entre a idealização e a realização do feito dá uma ideia do esforço que a Ciência demanda para analisar minuciosamente o Universo físico, exigindo muito empenho e concentração. Sabe-se, contudo, que a atenção do ser humano é limitada; o limiar de atenção - tempo que uma pessoa consegue ficar focada em determinada tarefa - gira em torno de 40 minutos para tarefas do cotidiano (Cornish and Dukette (2009)).

Assim, em um esforço para dar maior dinamismo às aulas de Estatística, foi criado o Momentinho Cultural (MC). É uma pausa com tempo determinado arbitrariamente pelo professor, com a função principal de descontrair o ambiente. Tal arbitrariedade fornece ao professor autonomia para, inclusive, não realizar o $\mathrm{MC}$ se assim julgar necessário.

'Momentinho' sugere uma pausa breve, enquanto 'Cultural' tem como objetivo nortear a discussão livre para assuntos mais elevados. Os temas abordados com maior frequência são Música, Teatro, Cinema e atualidades. Podem-se elencar alguns benefícios da aplicação do Momentinho Cultural:

- relaxa

- é divertido

- estimula a comunicação entre os alunos e o professor

- cria um ambiente para discussão de questões fundamentais que não encontram espaço no currículo formal.

Mas justiça seja feita aos mestres que já se utilizavam desta técnica, que foi transmitida ao autor pelo professor João Beal Vargas durante suas magnéticas aulas. Curiosamente outro sábio mestre - o sempre alegre José Baratojo - ensina sobre esta arte, intitulada 'zunzun' em seu conto 'Psicologia das cores', transcrito parcialmente a seguir.

“Alguns anos atrás recebi uma turma de alunos (47 alunas e 3 alunos) do Curso de Psicologia. Como podem imaginar, a parte da aula mais difícil não era referente aos assuntos da Matemática que eu devia ministrar-lhes, mas sim, fazer com que as alunas conseguissem parar de conversar.

Em primeiro lugar, entrei num acordo com aquele simpático e educado grupo, acordo esse que consistia em fazer de tempos em tempos, após a explicação de algum assunto, um momento que intitulamos de 'zunzun'. Desse modo, fomos até o fim do semestre bem entrosados."

José Baratojo, 2000, p. 47

In: M.A. Sorto (Ed.), Advances in statistics education: developments, experiences and assessments. Proceedings of the Satellite conference of the International Association for Statistical Education (IASE), July 2015, Rio de Janeiro, Brazil. 
Tom Lehrer - compositor, satirista, pianista e matemático de Harvard - teve papel fundamental na criação do MC. Suas músicas de alto teor político e satírico tiveram grande repercussão nos anos 50 e 60, obrigando Lehrer a reduzir sua carga na academia para se dedicar à vida artística. Os temas de suas canções giram em torno de assuntos controversos no meio acadêmico, como o plágio de ideias - discutido na sonora Lobachevsky - ou o consumo de bebidas alcoólicas e drogas, abordado com humor nas canções Bright college days e The old dope peddler.

Bradley Carlin compilou The Bayesian Singalong Book (O Livro de Canções Bayesianas, http://www.biostat.umn.edu/ brad/V9SingAlong.pdf), uma lista de paródias criada por Carlin e outros estatísticos como Morris DeGroot e George Box, que conta com canções famosas como Imagine de John Lennon e Oh, Pretty Woman de Roy Orbison. Tal lista está citada em Língua Portuguesa no apêndice de Paulino et al. (2003), intitulada "Uma amostra não aleatória de canções bayesianas".

Já no primeiro dia de aula pode-se utilizar o MC para obter algumas informações adicionais sobre os alunos, como o gosto musical ou cinematográfico. Tais informações podem ser utilizadas para direcionar exemplos e diferentes abordagens didáticas. No primeiro dia letivo de 2015, por exemplo, o autor identificou que aproximadamente metade da turma de Estatística Aplicada à Psicologia apreciava rock pesado. Pela experiência sabe-se que este é um grupo bastante objetivo e crítico, devendo-se considerar exemplos mais diretos e aplicados. É perceptível o envolvimento gradual dos alunos, que se sentem seguros para discutir temas de seu domínio, e que naturalmente os torna mais motivados para as discussões técnicas de sala de aula.

\section{PLAYLIST NO YOUTUBE ${ }^{\circledR}$ E O PROJETO BIOPHILIA ${ }^{\circledR}$}

"O que é que a Ciência tem? Tem lápis de calcular. Que mais que a Ciência tem? Borracha pra depois apagar."

Raul Seixas

“ E por que então esta vontade de parecer heroi ou professor universitário (aquela tal classe que, ou passa a aprender com os alunos - quer dizer, com a rua ou não vai sobreviver)?"

Tom Zé

O questionamento apresentado por Raul Seixas na canção 'Todo mundo explica' é uma alusão à limitação da Ciência, que tem o Universo físico como barreira a transpor. Tom Zé, por sua vez, faz uma crítica ao personagem do professor universitário em 'Complexo de épico', em que aponta a necessidade da conexão desta classe com a sociedade. As duas músicas integram a playlist do Momentinho Cultural no Youtube, cujo lema é 'músicas para estudar e pensar'. A lista conta também com canções de artistas como Maria Bethânia, Tom Lehrer e Frank Zappa, e está em constante atualização. Eventualmente os vídeos da playlist podem ser tomados como base para discussão em sala de aula, com enfoques variados como letra, construção musical, etc.

Dentre os vídeos listados está 'Thunderbolt', música que compõe o álbum Biophilia, lançado em 2011 pela cantora islandesa Björk Guðmundsdóttir. O Biophilia Educational Project (http://biophiliaeducational.org) é um projeto piloto de grande escala que conta com a participação de acadêmicos, cientistas, artistas, professores e estudantes de todos os níveis acadêmicos. Apresenta um exemplo de colaboração dinâmica entre diferentes áreas da sociedade, tais como instituições culturais, de ensino, ciência e pesquisa. O projeto foi originalmente desenvolvido por Guðmundsdóttir com apoio da prefeitura da cidade de Reykjavík e da Universidade da Islândia, em conexão com o lançamento do álbum. Baseia-se na criatividade como ferramenta de ensino e pesquisa, no qual música, tecnologia e ciências naturais estão ligados entre si de uma forma inovadora. Os principais objetivos são: 
- promover a inovação nas escolas através do desenvolvimento de métodos de ensino que combinam ciências naturais, criatividade e tecnologia

- acabar com as práticas tradicionais de ensino através de uma abordagem multidisciplinar, em todas as idades, assuntos e disciplinas.

Para criar um ambiente que contemplasse todos estes elementos, foi desenvolvido um aplicativo (https://www.youtube.com/watch?v $=\mathrm{n} 8 \mathrm{c} 0 \times 6 \mathrm{dO} 2 \mathrm{bg}$ ) em conjunto com a Apple Computers $^{\circledR}$, que apresenta interativamente as canções do álbum e seus elementos naturais, conforme Tabela 1.

Tabela 1. Faixas de Biophilia e suas referências naturais e musicais

\begin{tabular}{|c|c|c|c|}
\hline Faixa & Título & Elemento natural & Musicologia \\
\hline 1 & Moon & Fases da Lua & Sequências musicais \\
\hline 2 & Thunderbolt & Relâmpago & Arpejos \\
\hline 3 & Crystalline & Estrutura de cristal & Estrutura e ambientes espaço-musicais \\
\hline 4 & Hollow & DNA & Ritmo e velocidade \\
\hline 5 & Dark matter & Matéria negra & Escalas \\
\hline 6 & Mutual core & Placas tectônicas & Acordes \\
\hline 7 & Solstice & Eixo da Terra e Gravidade & Contraponto \\
\hline 8 & Sacrifice & Interação entre os sexos & Notação musical \\
\hline 9 & Cosmogony & Música de esferas & Equilíbrio \\
\hline 10 & Virus & Vírus & Música generativa \\
\hline
\end{tabular}

A música de esferas é um termo de origem pitagórica, associando a harmonia do universo com a música. Kepler (1967) publicou Mysterium cosmographicum (1596) e Harmonices mundi (1619), onde descreve tais associações e funda a música celeste. Música generativa é um termo cunhado por Brian Eno (1996) para descrever a música que é sempre diferente e muda a todo momento, sendo criada por um sistema.

No aplicativo, cada canção conta com um jogo didático, que permite ao estudante interagir simultaneamente com os elementos naturais e musicais. Em Virus, por exemplo, apresenta-se um ataque ao núcleo de uma célula, que pode ser impedido pelo estudante, mas implica na suspensão da música. Para ouvir a melodia completa é necessário deixar o vírus invadir a célula e espalhar o DNA até a degeneração celular completa, simulando o processo natural.

\section{VARIANTES DO MC}

Eventualmente o assunto sobre cultura pode não suscitar muita empolgação no grupo. Neste caso utiliza-se a versatilidade da sigla "MC", que pode facilmente assumir diversas formas:

- Momentinho Cultural

- Momentinho Cult

- Momentinho Cívico

- Momentinho Criativo

- Momentinho Culinário

- Momentinho Cinematográfico

- Momentinho Cultural Markov Chain Monte Carlo - MCMCMC - (MC) $)^{3}$

- ...

\section{PALAVRAS FINAIS}

As disciplinas de Estatística que compõem os currículos dos cursos das universidades brasileiras são historicamente conhecidas por concentrarem índices elevados de reprovação e evasão. Segundo Souza Filho et al. (2007), os cursos relacionados às Ciências Exatas - em especial Matemática e Computação - apresentam índices de evasão acima da média geral brasileira. Tais disciplinas, porém, são de fundamental importância para a sólida aplicação do Método Científico pelos profissionais das mais diversas áreas de formação. Sendo assim, o bom desempenho dos 
alunos nestas disciplinas é fundamental para a formação de profissionais qualificados que promovam o desenvolvimento científico e tecnológico do país.

No cenário atual, os universitários ingressantes apresentam deficiências profundas, em geral referentes a conteúdos da Educação Básica, implicando na dificuldade de acompanhamento das disciplinas e desinteresse por parte dos discentes. Por outro lado, quando o aluno sente-se estimulado e vislumbra possibilidades de obter sucesso em seu curso, diminuem as chances de que ele abandone a Universidade em um primeiro momento.

Muitas vezes as dificuldades encontradas desmotivam o aluno, que acaba por considerar-se incapaz de dar continuidade nos estudos, além de tornar-se inibido para se comunicar com os colegas e professores. Neste contexto, cabe aos professores, então, buscarem estratégias no sentido de dirimir esta situação.

Uma alternativa efetiva pode ser a utilização de técnicas que aproximem o aluno da sala de aula e de seus colegas e professores, promovendo a motivação para estudos mais árduos. Uma destas técnicas é sugerida neste artigo, uma vez que o Momentinho Cultural trabalha a afetividade do estudante, o estimula a discutir assuntos que sejam de seu interesse e o coloca como agente ativo dentro da sala de aula. Com o aluno motivado e sentindo-se parte ativa do contexto da aula, é possível promover uma aprendizagem mais significativa. Ausubel (2003), ao tratar da Teoria da Assimilação e Retenção Significativas, afirma que tanto as variáveis cognitivas quanto as afetivas e emocionais fazem parte desse processo, podendo interferir na aprendizagem de forma positiva ou negativa. Sendo assim, a ideia do Momentinho Cultural é fazer com que as variáveis afetivas e emocionais possam interferir de forma positiva na aprendizagem significativa dos conteúdos trabalhados nas aulas de Estatística.

\section{REFERÊNCIAS}

Ausubel, D.P. (2003). Aquisição e retenção de conhecimentos: uma perspectiva cognitiva. Lisboa: Plátano Edições Técnicas.

Baratojo, J.T. (2000). Fatos, contos e piadas da sala de aula. 56-57, Porto Alegre.

Carlin, B. The Bayesian Singalong Book. URL http://www.biostat.umn.edu/ brad/V9SingAlong.pdf. Acesso em 25/04/2015.

Cornish, D. \& Dukette, D. (2009). The essential 20: twenty components of an excellent health care team. Dorrance Publishing.

Eno, B. (1996). Generative Music. http://www.inmotionmagazine.com/eno1.html. Acesso em $25 / 04 / 2015$.

Gelman, A., \& Nolan, D. (2002). Teaching statistics: A bag of tricks. Oxford University Press.

Guðmundsdóttir, B. Biophilia Educational Project http://biophiliaeducational.org, https://www.youtube.com/watch?v=n8c0x6dO2bg. Acesso em 25/04/2015.

Guðmundsdóttir, B. (2011) Thunderbolt [Recorded by Björk Guðmundsdóttir]. On Biophilia [CD], Location: One Little Indian. (2008-2011)

Kepler, J. (1967). Kepler's Somnium: The Dream, Or Posthumous Work on Lunar Astronomy. Courier Corporation.

Lehrer, T (1959). Bright college days [Recorded by Tom Lehrer]. On More of Tom Lehrer [LP], Location: Lehrer Records. (1959)

Lehrer, T (1953). Lobachevsky [Recorded by Tom Lehrer]. On Songs by Tom Lehrer [LP], Location: Lehrer Records. (1953)

Lehrer, T (1953). The old dope peddler [Recorded by Tom Lehrer]. On Songs by Tom Lehrer [LP], Location: Lehrer Records. (1953)

Paulino, C. D. M., Turkman, M. A. A., \& Murteira, B. (2003). Estatística bayesiana. Fundação Calouste Gulbenkian.

Souza Filho, R.L.L. ET AL. (2007) A Evasão no Ensino Superior Brasileiro. In: Cadernos de Pesquisa, 37(132), set./dez. 